\section{Prophylactic compression after breast cancer surgery}

\author{
Katarzyna Ochałek, ${ }^{1,2}$ Hugo Partsch, ${ }^{3}$ \\ Zbigniew Szygula ${ }^{4}$
}

${ }^{1}$ Department of Clinical Rehabilitation, Faculty of Motor Rehabilitation, University of Physical Education, Krakow, Poland; ${ }^{2}$ Lymphedema Clinic, Krakow, Poland; ${ }^{3}$ Medical University of Vienna, Vienna, Austria; ${ }^{4}$ Department of Sports Medicine and Human Nutrition, Faculty of Physical Education and Sport, University of Physical Education, Krakow, Poland

\section{Introduction}

Breast Cancer - Related Lymphedema (BCRL) remains one of major long-term complications of oncological treatment. Axillary lymph node dissection, sentinel lymph node biopsy and radiotherapy are associated with development of BCRL by damage of the distribution or function in the lymphatic system of the axilla. ${ }^{1-3}$ Despite different attempts, scientific evidence concerning prevention of BCRL remains still poor. ${ }^{4,5}$ In a previous randomized controlled trial it has been demonstrated that arm compression sleeves (CG) in class 1 (ccl1, 15$21 \mathrm{mmHg}$ ) worn immediately after breast cancer surgery including axillary lymphnode removal in addition to physical therapy are able to reduce the occurrence of early postoperative swelling and of arm lymphedema up to one year. ${ }^{6}$ The available data indicated also that $\mathrm{CG}$ neither interfere with the level of physical activity nor decrease quality of life 1 year after breast cancer surgery. ${ }^{7}$

Aim of the present investigation was to check the further development of the arm swelling in patients using compression sleeves or not, and to compare the quality of life in women treated due to breast cancer two years after surgery.

\section{Materials and Methods}

From 45 patients recruited at the beginning, after two years 1 patient from CG died and 3 patients ( 2 from $\mathrm{CG}, 1$ from $\mathrm{NCG}$ ) resigned, finally 41 patients (20 in CG and 21 in NCG) have continued prophylactic management including circular-knit sleeves in class 1 (ccl1, 15-21 $\mathrm{mmHg}$ ) for daily wearing with physical exercises (CG) or physical exercise without compression (NCG) in post-operative period. Compression sleeves delivered by the same factory (MEDI Bayreuth, Germany), were fitted based on the individual limb measurements and exchanged every six months.

\section{Results}

CG showed significantly lower mean affected arm volume compared to NCG $(\mathrm{P}=0.023)$ after 2 years. Three from 20 patents in the CG and 6 from 21 in NCG showed arm lymphedema, defined by an increase of the arm volume exceeding $10 \%$ compared to the preoperative values. Significant improvement of several parameters QOL (QLQ-C30 and QLQ-BR23 questionnaires) were found in the compression group.

\section{Conclusions}

Light compression sleeves worn for 2 years are not only able to reduce the incidence of early postoperative edema and of lymphedema, but also lead to a significant improvement of important quality of life parameters like physical functioning, fatigue, pain, arm and breast-symptoms and future perspectives.

\section{References}

1. Monleon S, Murta-Nascimento C, Bascuas I, et al. Lymphedema predictor factors after breast cancer surgery: a survival analysis. Lymphat Res Biol 2015;4:268-74.
Correspondence: Katarzyna Ochałek, Department of Clinical Rehabilitation, University of Physical Education, Al. Jana Pawla II 78 PO Box: 62, 31-571 Krakow 49, Poland.

Tel.: +48604057505 .

E-mail:k.ochalek@wp.pl

Conference presentation: International Compression Club (ICC) Meeting, Rotterdam, 2018.

This work is licensed under a Creative Commons Attribution 4.0 License (by-nc 4.0).

(C) Copyright K. Ochatek et al., 2018

Licensee PAGEPress, Italy

Veins and Lymphatics 2018; 7:7993

doi:10.4081/vl.2018.7993

2. Ugur S, Arici C, Yaprak M, et al. Risk factors of breast cancer-related lymphedema. Lymphat Res Biol 2013;2:725.

3. Baker A, Semple J, Moore S, Johnston M. Lymphatic function is impaired following irradtion of a single lymph node. Lymphat Res Biol 2014;2:76-88.

4. Rogan S, Taeymans J, Luginbuehl H, et al. Therapy modalities to reduce lymphedema in female breast cancer patients: a systematic review and metaanalysis. Breast Cancer Res Treat 2016;159:1-14.

5. Greenlee H, Balneaves L, Carlson L, et al. Clinical Practice Guidelines on the Use of Integrative Therapies as Supportive Care in Patients Treated for Breast Cancer. J Natl Cancer Inst Monogr 2014;50:346-58.

6. Ochalek K, Gradalski T, Partsch H. Preventing early postoperative arm swelling and lymphedema manifestation by compression sleeves after axillary lymph node interventions in breast cancer patients: a randomized controlled trial. J Pain Symptom Manage 2017;3:346-54.

7.Ochalek K, Gradalski T, Szygula Z, Partsch H. Physical activity with and wwthout arm sleeves: compliance and quality of life after breast cancer surgery. A Randomized Controlled Trial. Lymphat Res Biol 2017 [Epub ahead of print]. 